JOSIP HABAZIN, mag.ing.traff. ${ }^{1}$

(Corresponding author)

E-mail: josip.habazin@gmail.com

ANTONIA GLASNOVIĆ, mag.ing.traff. ${ }^{1}$

E-mail: aglasnovic11@gmail.com

IVONA BAJOR, Ph.D. ${ }^{1}$

E-mail: ibajor@fpz.hr

${ }^{1}$ University of Zagreb,

Faculty of Transport and Traffic Sciences

Vukelićeva 4, 10000 Zagreb, Croatia
Internal Transport

Preliminary Communication

Submitted: 20 Mar. 2016

Accepted: 16 Nov. 2016

\title{
ORDER PICKING PROCESS IN WAREHOUSE: CASE STUDY OF DAIRY INDUSTRY IN CROATIA
}

\begin{abstract}
The proper functioning of warehouse processes is fundamental for operational improvement and overall logistic supply chain improvement. Order picking is considered one of the most important from the group. Throughout picking orders in warehouses, the presence of human work is highly reflected, with the main goal to reduce the process time as much as possible, that is, to the very minimum. There are several different order picking methods, and nowadays, the most common ones are being developed and are significantly dependent on the type of goods, the warehouse equipment, etc., and those that stand out are scanning and picking by voice. This paper will provide information regarding the dairy industry in the Republic of Croatia with the analysis of order picking process in the observed company. Overall research highlighted the problem and resulted in proposals of solutions.
\end{abstract}

\section{KEY WORDS}

warehousing; order picking; performance analysis; supply chain; type of goods;

\section{INTRODUCTION}

Processes which occur in warehouses are of large importance for the circulation of goods throughout the supply chain. Warehousing itself refers to taking care, transportation, loading, unloading, packing and processing of goods between the production and consumption for commodity and other various functions. According to authors Bartholdi and Hackman [1], the warehouse process of order picking takes $70 \%$ of time and $55 \%$ of costs which makes it a significant process in a warehouse. The order picking process can be one-dimensional, two-dimensional and three-dimensional. The main purpose of this paper is through a case study to implicate how a two-dimensional order picking in a warehouse affects the processing and whether the observed warehouse has optimal processing assigned.
The warehouse included in the case study stores dairy products in diverse sizes and weights, where in accordance to specific temperature regime, short lifecycle, etc., the processing is defined in a way as tailor-made for a company. To analyse and measure the effectiveness, according to Richards [2], it is necessary to approach the processes from where the deficiencies can be indicated. The same approach is conducted regarding the provided case study, where detailed measuring and analysis are focused on the order picking at the observed warehouse on the Croatian market with over 9,000 storage locations.

Regarding the dairy industry in the Republic of Croatia, according to the Croatian Bureau of Statistics and the data from 2014, it is compiled of 117 companies with 4,992 employees. The market itself includes an assortment of packaged dairy products which comprises the following: cheese, drinking milk products, yoghurt and sour milk products, and other products such as chilled and shelf stable desserts, chilled snacks, cream, etc. [3]

\section{WAREHOUSE SYSTEMS PROCESSES}

Basic warehouse processes are the following: receiving, put-away, internal replenishment, order picking, accumulating and sorting, packing, cross docking, dispatch and shipping. Receipt and storage are considered inbound processes, while others are considered outbound processes. Previously noted is shown in Figure 1. Beside these processes, there are also value-added services which are not obligatory but depend on the warehouse type and various provided services [2].

In various warehouses, goods which usually enter as units of a larger scale, go through reorganization submitted to repackaging that results with units of a smaller scale. At the observed warehouse typical example are large packages of milk which arrive in a warehouse as pallet quantities. Afterwards, they are broken down into smaller quantities throughout order 


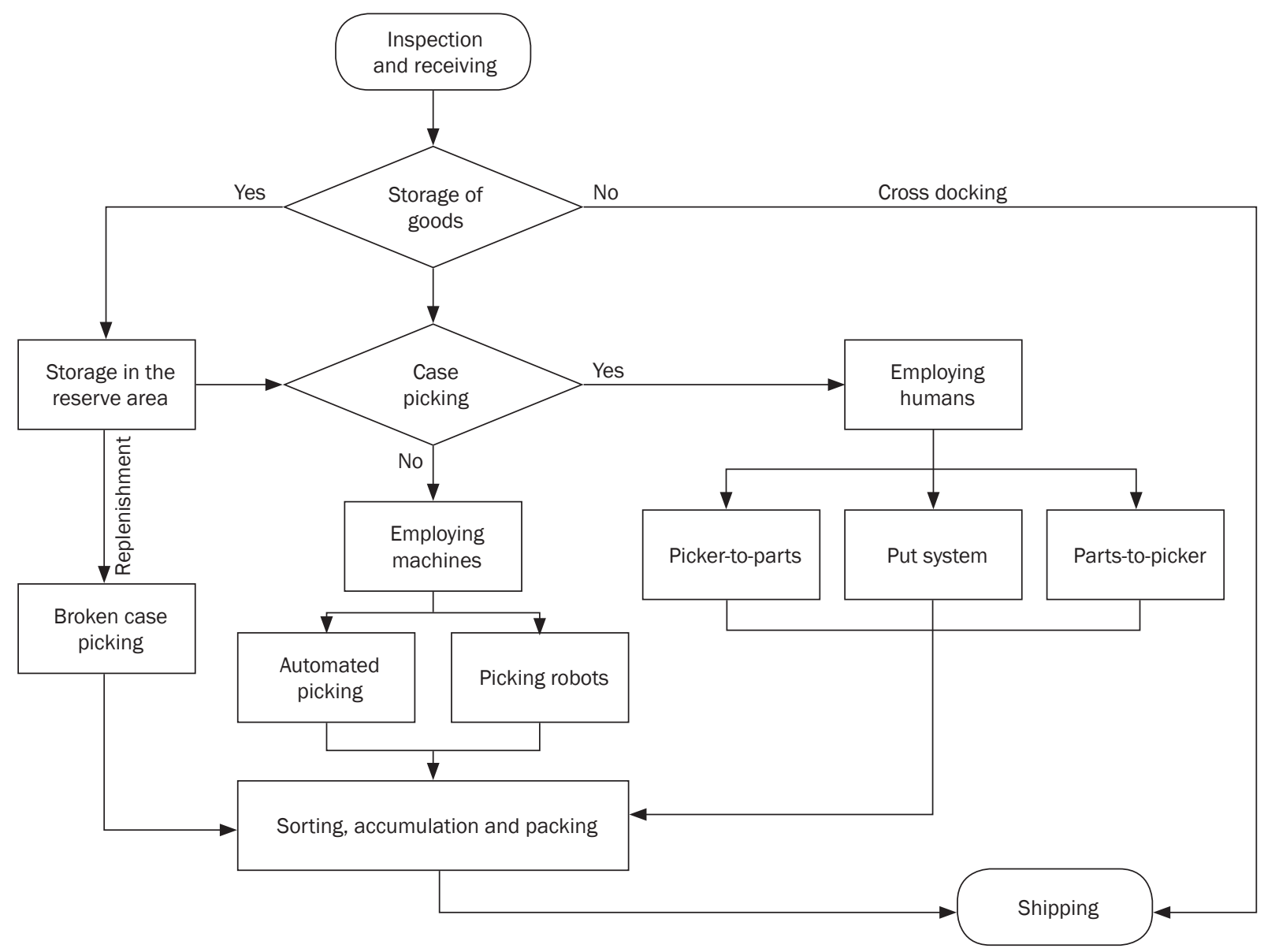

Figure 1 - Typical warehouse processes

picking, packing and finally distribution. In this kind of warehouses, operations which are done daily are tied with human performance and greatly depend on it. The smaller the handling unit, the greater the handling cost. Smaller units require more labour and much more processing to be delivered. Precisely, pallet manipulation at a warehouse directly influences the time used for picking. This results with accurately collected units which are then forwarded to the next process [2].

\subsection{Receiving}

First in line of warehouse processes is receiving of goods. This process does not take as much time as picking, which is shown onwards, but it is as relevant as any. Especially, if incorrect put-away occurs and causes errors in further processing [2]. The process of receiving can begin with the notice of the goods arrival. This permits the warehouse to prepare, to schedule inbound operations so there are no uncoordinated events. With arrival, unloading begins after which units are put away with accurate documenting before.

If there is necessity for labelling, this process occurs before goods are put away. In every warehouse a place must be preordained for these actions. If there is no such place, but it is known that some of the arriving products must be labelled, a temporary place must be determined.

Products typically arrive in a warehouse in larger units, as it has been mentioned before, on pallets. If pallets are not arranged homogeneously they have to be broken down into separate cartons [1]. It is necessary for receiving that the method of delivery is compatible with the unloading equipment in the receiving warehouse. Otherwise, the need for additional equipment arises [2]. Altogether, the process of receiving accounts for only $10 \%$ of the operating costs in a typical warehouse, but it is supposed to be reduced by the use of Radio-frequency Identification (RFID) [1].

\subsection{Put-away}

Every Stock Keeping Unit (SKU) in a warehouse has its own location, determined in advance, whether the positioning is predefined or random. Precisely, there are several storage policies. A predefined storage policy prescribes a particular location for SKU to be stored, but random policy leaves the decision to the operator. Both of these storage policies can be used in some warehouses. Furthermore, a class-based storage system allocates zones to specific product which is based upon products turnover rate as $A B C$ zoning. 
Another storage policy includes correlated storage of family groups, that is, storing products at nearby positions if they are often required simultaneously [4].

This step in the process is of large importance. It can reduce time defined for picking and in the end decrease total duration of outbound processes. For putaway the inventory management needs to be correct and up to date. It must be known at all times what storage locations are available, how much weight they can bear, etc. In this case, the secondary inventory management must be managed, not of products, but of locations in order to know everything mentioned. After the product is placed on its location, the storage location should also be scanned to record where the unit has been placed. This kind of information will be of use when it is needed to pick orders [1].

There are several options for inbound SKU. First is inbound into high-density storage like drive-in racking, next is inbound into standard wide aisle reserve slots such as upper levels. The last is inbound into pick slots which are ground-level wide aisle racking. The latter is represented in a small amount of products with no current stock [2].

Put-away process may require a large amount of work because SKUs must be moved over significant distances to their storage position. Put-away accounts for approximately $15 \%$ of warehouse operating costs [1].

\subsection{Order picking}

The process of order picking in a warehouse involves selecting and gathering specified amount of right SKUs in accordance with the order and it is composed of lifting, moving, picking, putting, packing, and other related activities [5].

During the order picking process, the orders are generally assigned to several pickers. However, in order to prevent control problems, the total pick area is often divided into picking zones. After this, the zones are generally served by different pickers, through the zoning policy. Orders are picked one by one or in batches in a predetermined order [4]. Further, order picking can be manual or automated. In manual order picking, the picker gathers units from their locations and then transports them to a packing area. Picking time $T_{p}$ is calculated as shown below.

$T_{p}=t_{1}+t_{2}+t_{3}+t_{4}$

where:

$t_{1}$-average travelling time [s];

$t_{2}$-average extracting and searching time [s]:

$t_{2}=x_{1} \cdot x_{2} \cdot t_{i}\left(x_{1}-\right.$ average number of locations per order [pieces], $x_{2}$ - average number of positions per location [pieces], $t_{i}$ - time needed for picking on one position (3-6) [s]);

$t_{3}$-information processing time $[s]: t_{3}=(10-15 s) \cdot x_{1}$; $t_{4}$-time for additional activities [s] $\left(t_{4}=75-300\right.$

$\mathrm{s}$ for hand pallet truck, $t_{4}=70-250 \mathrm{~s}$ for low-

level order picker, $t_{4}=55-200 \mathrm{~s}$ for high-reach forklift).

In the case of automated picking, that is, automated storage and retrieval systems, system retrieves one or more unit loads and place them to a picking station. After that, the picker takes products on orders, and the remaining items on the unit loads are transferred to storage again [5]. The picking systems classification is shown in Figure 1.

\subsection{Packing}

The process of packing can be demanding because every previously picked unit is generally handled separately. At this time, the process of checking the picked order is also required and convenient and there is less chance for errors to occur. Order accuracy is a crucial measure of service to a customer. If inaccurate orders make it to the customer, there will appear new expenses such as returns, which are expensive to handle. This process must be dealt with caution and awareness. The basic task of packing is to prepare goods for further transportation by any carrier in a way that does not affect shipping costs in a negative manner. If there is a complication with picking orders, there will be complication with packing. Precisely, if all items from the order are not positioned at the same time at a packing area, it is likely that the shipment will be delayed or/and costs will increase. The shipment can be sent partially resulting in higher costs [1].

\subsection{Shipping}

The process of shipping is the final process amongst warehouse processes. After packing and preparing units for shipping (consolidation), the first step is loading into transportation vehicles with the assumption that the shipping methods have been previously arranged. This process is not as complex and generally includes less labour than mentioned before, although there can be some additional activities if the product is being staged before being loaded [1]. Also outbound zone can include control, which will often occupy at least one warehouse worker to provide the activity. Depending on the warehouse information system, control can be done manually or using a scanner.

\section{COLLECTION OF ORDERS IN A WAREHOUSE - ORDER PICKING}

Of all the above mentioned warehouse processes, collecting orders is the most important and most challenging for optimization. Collecting orders or order picking is defined as picking from storage locations based on customer requirements. According to Bartholdi and Hackman [1], collecting orders in the 
warehouse wastes the largest share of time of all warehouse activities, approximately $70 \%$. Therefore, it is very important to minimize the pickers' collection time and picking route. Affecting the mentioned total collection time by order decreases, and the number of successfully collected orders per hour increases.

When collecting orders, it also appears that the largest share of work is done by warehouse workers. In order to meet large orders of many customers, the warehouses have several shifts performing tasks of collecting orders. From an economic point of view collecting orders makes up to $55 \%$ of operating costs in the warehouse. Therefore, it is important to reduce the order picking cost by optimizing time and picking route because it greatly reduces the overall storage costs. Annual operating costs in warehouses are shown in Figure 2.

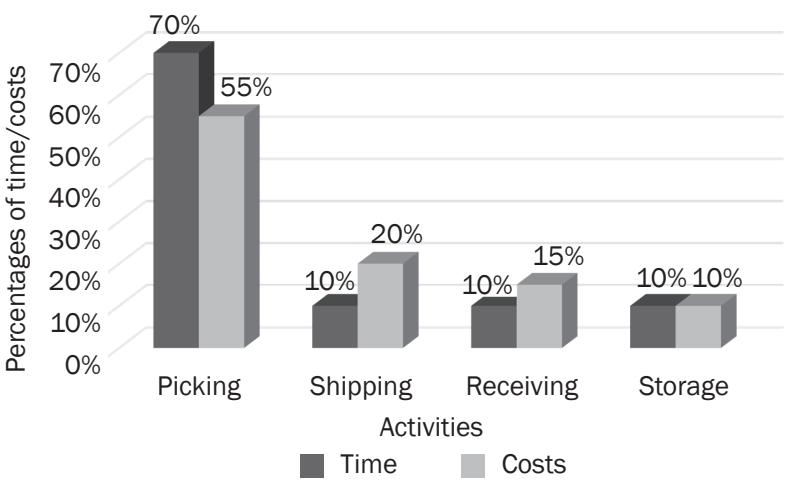

Figure 2 - Percentage of annual operating costs in a warehouse

\section{WAREHOUSE PROCESS OPTIMIZATION}

The research given in this study implicates the problems at the observed warehouse from which certain data were collected. The methodology of research consists of data collected from WMS and data collected chronographically at the location. Also, various authors suggest different answers to related similar problems regarding warehouse process optimization.

According to Saif and Elhedhli [6], cold supply chains have high levels of greenhouse gas emissions due to high energy consumption and refrigerant gas leaks and for this problem the solution consists of dealing with managing inventory by using a known policy but without explicit formulas for the inventory cost and maximum level functions. Precisely, a nove hybrid simulation-optimization approach is proposed for problem solving. Lagrangian decomposition is used to compose the model into an integer programming sub-problem and sets of single variable concave minimization sub-problems that are solved using the simulating approach. The formula given by the named authors combines the efficiency of optimization methods with the accuracy of simulation methods. By using it, not only is the process optimization reached, but the warehouse processes are also turning green and sustainable.

Author Lu [7] conducted research for an algorithm for dynamic order-picking in warehouses, and according to it, the dynamic order-picking strategies that allow changes of pick-lists during a picked cycle are of importance. In this paper, authors gave the routing algorithm for optimizing the dynamic order picking routes for a manual picker to part system, which is also used in the warehouse described in the main research of this study.

According to Thomas and Meller [8], their guidelines can provide a warehouse design close to the optimal solution; precisely, they limit the decision variables and include size and layout of the shipping area, dock door configuration, pallet shape and pallet rack height. For developing the design guidelines, they employ a statistical-based methodology, where one set of data is used to develop the guidelines and an independent set of data is used to evaluate the performance of the guidelines. The response variable is the number of labour hours which is evaluated for each design in the solution space, but the most impactful parameter is using a forward area.

Authors Pazour and Carlo [9] refer to warehouse reshuffling as a reorganization strategy and claim that it can be optimized using a mathematical programming formulation, based on heuristics. The given results suggest that the proposed heuristics improves upon a benchmarking heuristics by relaxing how cycles are handled and incorporating double-handling. It is necessary to emphasize the problem given in this, and also include double-handling.

According to Rakesh and Adil [10], the warehouse layout decision is important as it affects several aspects of a warehouse, including various costs and storage capacity. Step toward warehouse optimization is by use of their algorithm that determines lane depth, number of storage levels, lateral depth and longitudinal width of a three-dimensional order picking warehouse. It also helps in knowing the quantum of change in the cost due to change in different parameters, which is difficult to predict due to the interaction of multiple effects and trade-offs.

Authors Kang and Kim [11] also base their research on Lagrangian relaxation, precisely on a heuristic algorithm based on Lagrangian relaxation and sub-gradient optimization methods. The use of this algorithm is planned for minimizing the sum of warehouse operation costs, inventory costs and transportation costs.

Reducing the travel distance in order picking is of significant importance in every warehouse. Accordingly, author Zhang [12] developed a Correlated Storage Assignment Strategy (CSAS) in order to reduce the travel distance in the picker-to-parts order picking system. In the conducted study, the use of the developed 
algorithm, compared with the full-turnover storage, reduces maximal $2.08 \%$ of the average travel distance per picking.

Authors Lu et al. [7] developed an interventionist routing algorithm for optimizing dynamic order picking. The algorithm re-calculates the optimal route during the picking operation and is tested using a set of stimulations based on an industrial case. The results given in this study indicate that, under a range of conditions, the algorithm can outperform both static and heuristic dynamic order picking routing algorithms.

The conducted research in the form of a case study will implicate how certain organizational changes may contribute to reducing the process time and influence higher quality processing. Based on warehouse processes of dairy industry on the Croatian market, the paper will suggest process optimization. On-site data collection, continuous process management and control can optimize the observed warehouse process, with the limitation of optimal process life cycle duration, regarding the possibility of upgrading in a certain upcoming period.

\section{ANALYSIS OF ORDER PICKING PROCESS AT DAIRY INDUSTRY ON THE CROATIAN MARKET}

In the form of a case study the research has been conducted at the dairy industry company located in the Republic of Croatia, a member of the large European corporation with their products distributed to multiple countries in Europe and to other continents. The industry has several warehouses in Croatia, while the main warehouse included in the case study is located in Zagreb. The aforementioned warehouse with their 9,190 storage locations is positioned next to the production facility constantly receiving quantities of finished products; also finished goods by road transport are received from other production facilities across the country. For the conducted research the order picking process has been analysed, where the specifications of layout, zones, order picking methods are studied in detail for the benefit of proposing optimal process solutions.

The observed warehouse is composed of several zones (D, G, C, M, L) which have been added over the years. The warehouse has a total of 14 loading docks, out of which three are located in the $D$ zone, nine in the $\mathrm{G}$ zone and two in the zone L. Zone $\mathrm{D}$, or high rack warehouse consists of 14 rows that with five levels can accommodate up to 3,800 pallets of finished products. In this zone the temperature is maintained at about $4^{\circ} \mathrm{C}$ and is used to store perishable dairy products. $\mathrm{D}$ zone layout is shown in Figure 3.

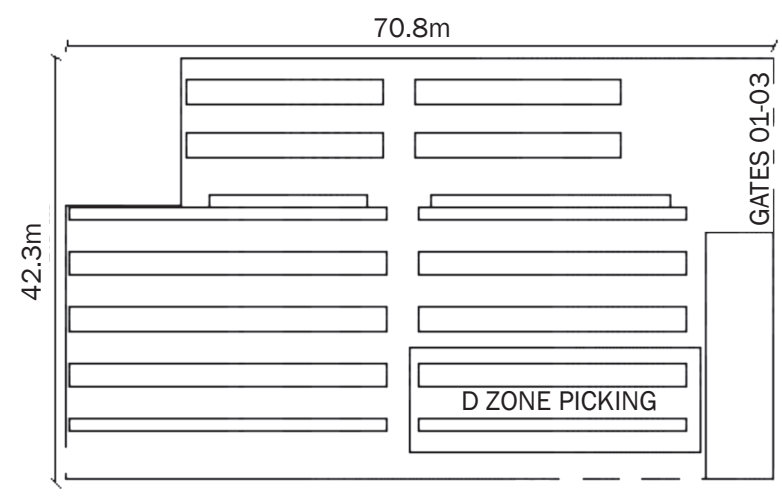

Figure 3 - Layout of D Zone in Central Warehouse Zagreb

Furthermore, zone G contains a total of 990 storage locations for perishable products with provided same temperature. G zone is shown in Figure 4.

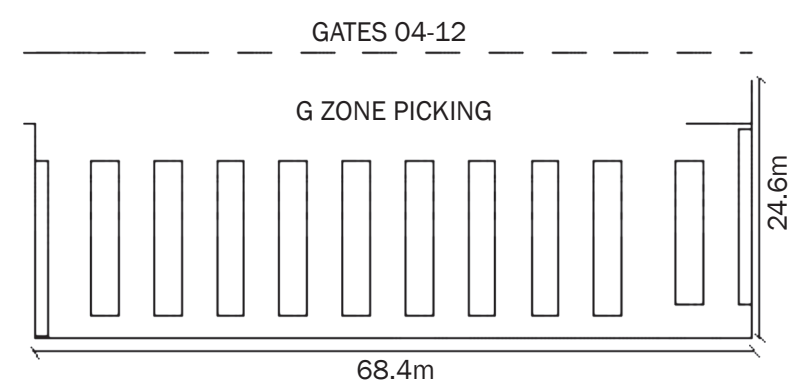

Figure 4 - G Zone layout in Central Warehouse Zagreb

Zone $\mathrm{M}$ is high rack warehouse with a total capacity of 4,400 storage locations, which is used for Ultra High Temperature (UHT) products, and it is not temperature controlled. It is important to mention that $\mathrm{M}$ zone is a fully automated storage facility, where goods are computer system ordered, with robotic cranes exempt and delivered to $L$ zone with the help of warehouse transporters. The observed warehouse with its areas is shown in Figure 5.

Picking is performed in two or three shifts and all of the mentioned zones are included in the process of picking. All three systems of order picking are performed, picking pieces, boxes and pallets. Part to picker is used in the $\mathrm{M}$ zone and serves only to extract the pallets that are later transported with the help of warehouse workers to the loading docks or used as filling for picking positions on a picker-to-part.

All positions at order picking picker-to-part intended for exempting goods according to customer orders are placed at zero level. In zone D the pickers have at their disposal about 80 pallet positions while in zone $G$ they have 330. In addition to these two zones, there is zone $\mathrm{C}$ which is comprised of shelves, which, on 60 positions contain portions of bulk items that have been returned by the truck driver as a surplus. All of these zones and picking positions on a picker-to-part are also shown in Figure 5. 


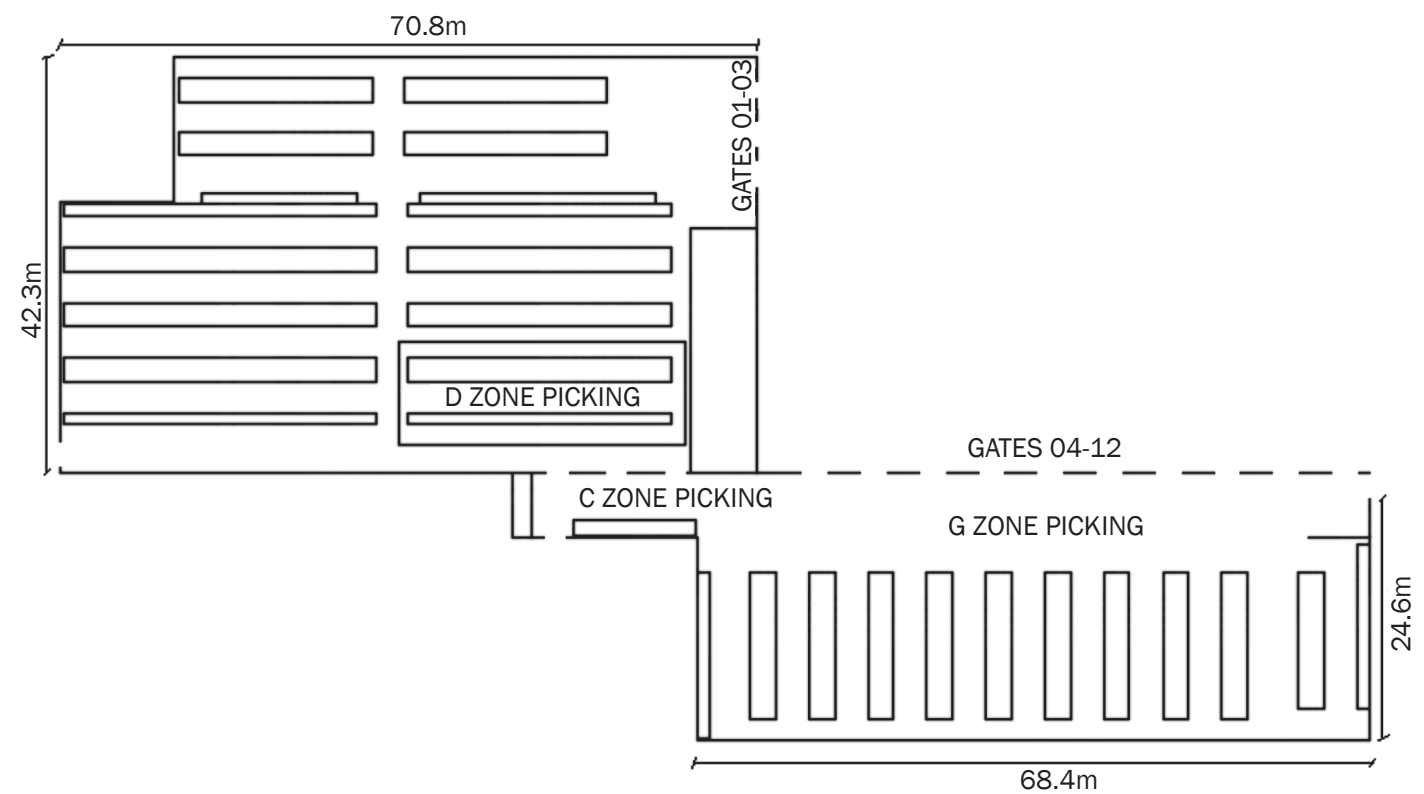

Figure 5 - Total layout of Central Warehouse Zagreb

Picking is performed with a scanner controlled by Warehouse Management System (WMS) which systematically leads the picker through the whole process of order picking. In zone D intended for picking positions are heavy-weight units and each order starts right in the D zone. After zone D, WMS sends pickers in zone $G$ where all other units are placed and where WMS systematically leads between 22 racks, visiting racks in the order from G-1 to G-22. After completing the task, the picker is required to stretch wrap a pallet, and position it to the loading dock according to instructions of the WMS system. For filling the empty positions in the warehouse, the company uses Hyster's R16H high rack forklifts. In order picking on a picker-to-part, the pickers use electric forklifts suitable for picking, model Linde 12.

Observing the picking process on the picker-to-part principle, several disadvantages were noted, crucial in maintaining KPI performances. To achieve its goal each picker is obliged in its shift to collect a minimum of 190 cases net per hour. The net productivity includes order picking time, i.e. the time from receiving the order to the final activity of issuing the certificate to the printer at the end of order picking. The gross time of order picking includes net time, time dedicated for pallet wrapping and time needed to deliver pallet at the loading docks. The average number of net boxes per hour in 2015 is 220.89 boxes per hour and the average number of gross boxes per hour in 2015 was 172.90 boxes.

During the second shift within a week, six different pickers are included in research. Each of the six pickers characterize different walking speeds, a variety of picking methods and that is the reason why the output results are in a wide range. During the study, the number of boxes is recorded, as well as the number of positions and the time required to complete each order picking task. The values obtained during the study are shown in the graph, data include 42 orders, with highlighted number of boxes and positions in the observed warehouse. In Figure 6 the time needed for picking an order is implicated, as the maximum time for picking order is 00:26:34, for 82 boxes on 47 positions.

Regarding order collection, during research it was noted that heavy products positioned between the $13^{\text {th }}$ and $15^{\text {th }}$ rows in the $\mathrm{G}$ zone create certain problems. When pickers arrive on positions between the $13^{\text {th }}$ and $15^{\text {th }}$ row they already had a $50-70 \%$ loaded pallet with boxes from previous positions. Heavy products must be placed first on the pallet bottom because they can disrupt the stability and damage lightweight products below. During the research it was noted that every sixth picking order includes three to ten boxes of heavy products needed to be collected from the mentioned positions. At this point, every picker must reorganize his pallet for what is needed certain time. During the reorganization, the pallet picker wastes time, occupies transport area between the rows and unnecessarily loses their own energy.

The proposal solution for the mentioned problem is relocation, precisely, the relocation of heavy products from locations G-13 to G-15 to front part of the G zone. If heavier products were to change their location, the problem with possible collisions and eventual bottlenecks would be expected to stop. There would not be any necessity for pallet reorganization, neither would picking take as much time as it does now. Regarding the picker and his constant need for reorganizing pallets, moving and heavy lifting, this kind of repeating actions can cause problems and decrease his work 


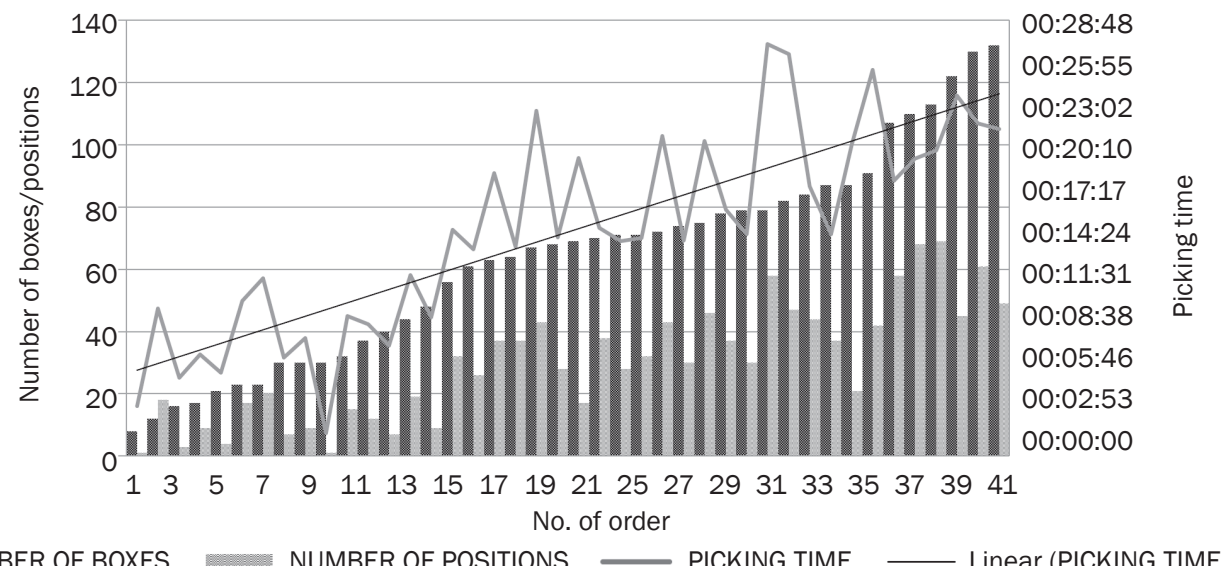

Figure 6 - Picking time without reorganization
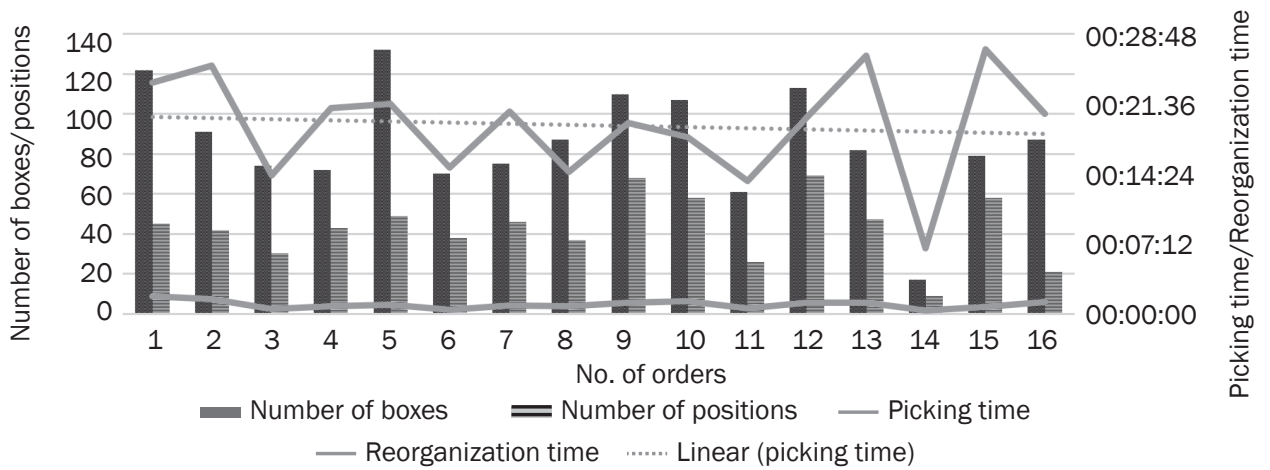

Figure 7 - Picking time with reorganization

ability, but by changing locations these actions would be expected to be reduced. Furthermore, the picking time would decrease for the amount of time dedicated to reorganize units. This is proposed by Figure 7 where for example the same order described in Figure 6, has 00:01:09 minutes of reorganization in its total picking time.

Relocating heavy products at the beginning of the $G$ zone does not require high investments, regarding neither time nor labour. The proposal for positioning the group of heavy products in the picking part of $G$ zone is shown in Figure 8.

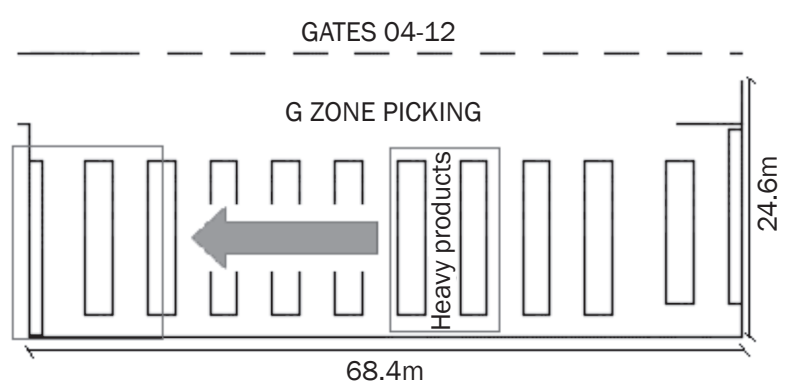

Figure 8 - Picking layout of G zone with problem solution

While conducting the research, another problem occurred during the order picking when the picker travels to zone $\mathrm{C}$ that consists of units returned from the distribution and dedicated for priority picking due to the positioning on virtual location. When the picker needs to collect for example 15 units and 14 are located on G-11-7, if the same unit is positioned at $\mathrm{C}$ zone, after collecting 14 pieces on $\mathrm{G}$ position the picker is sent to $C$ zone to collect one unit, then the picker continues picking. After analysing 43 orders the problem occurred in nine orders which are shown in Table 1. The table implicates positions at G, D and $\mathrm{C}$ zones with exact location numbers, as position 'G-13-4' implies that the pallet position is at $\mathrm{G}$ zone, $13^{\text {th }}$ row, $4^{\text {th }}$ position.

In practice, scanners send pickers from $D$ to $G$ zone while $\mathrm{C}$ zone is located between these two zones. Hence, if order consists of the product from zone $\mathrm{C}$, the scanner should have the ability to send pickers to $\mathrm{C}$ positions when they are passing near the zone. This problem can be optimized with giving position $\mathrm{C}$ priority over position $\mathrm{G}$, through administration interface in WMS. By adjusting like proposed, the reduction of the picking time is expected. The mentioned observations generally occur as a result of insufficiently thorough analysis when setting the zone picking.

Modifications need to be undertaken directly to the WMS system, first in line for picking to be set as $\mathrm{D}$ zone, $\mathrm{C}$ zone and in the end the $\mathrm{G}$ zone. This will 
Table 1 - Time spent for unnecessary travel to position C

\begin{tabular}{|c|c|c|c|c|c||}
\hline ORDER NUMBER & $\begin{array}{c}\text { ZONE G } \\
\text { POSITION }\end{array}$ & $\begin{array}{c}\text { ZONE D } \\
\text { POSITION }\end{array}$ & $\begin{array}{c}\text { ZONE C } \\
\text { POSITION }\end{array}$ & $\begin{array}{c}\text { NEXT } \\
\text { POSITION }\end{array}$ & $\begin{array}{c}\text { TIME LOST G/D-C } \\
\text { [min] }\end{array}$ \\
\hline \hline 1 & - & D-10-15 & C-1-045 & D-10-19 & $0: 39: 12$ \\
\hline 2 & G-13-4 & - & C-1-028 & G-13-06 & $1: 16: 59$ \\
\hline 3 & G-02-01 & - & C-1-010 & G-03-08 & $0: 27: 26$ \\
\hline 4 & G-09-17 & - & C-1-012 & G-10-03 & $1: 09: 11$ \\
\hline 5 & - & D-11-22 & C-1-003 & D-11-17 & $0: 41: 20$ \\
\hline 6 & G-01-06 & - & C-1-009 & G-01-10 & $0: 35: 30$ \\
\hline 7 & G-11-11 & - & C-1-030 & G-11-11 & $1: 13: 44$ \\
\hline 8 & G-20-04 & - & C-1-013 & G-21-13 & $1: 37: 40$ \\
\hline 9 & G-15-17 & - & C-1-022 & G-16-06 & $1: 27: 02$ \\
\hline
\end{tabular}

significantly save time for the picker as stated earlier in this paper. The layout with the proposed location visit order is shown in Figure 9.

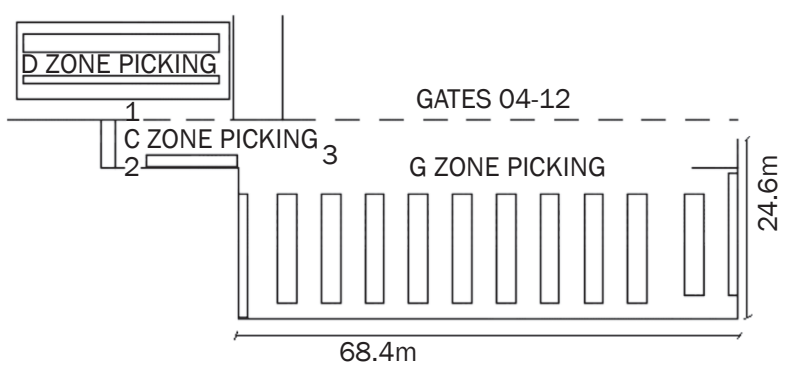

Figure 9 - Picking layout of Central Warehouse Zagreb with picking by priority

\section{CONCLUSION}

Storing dairy products, considered sensitive goods that need to be under special temperature regime generally implies similar processing as storing other types of finished goods. Every process, from receiving until shipping is as well vital, while order picking is also the one that accounts for the majority of warehouse operating costs and requires the most performing time. Once the picker starts gathering products from orders, they walk, move, lift, put, pack and do other related works which take time and in that way become costs.

The dairy company researched in a form of a case study on the Croatian market is well organized while the analysis implicates certain possibilities for the optimization within order picking process which is common in every company due to the fact that every process has a lifecycle.

To perform a suggestion of a solution, the order picking process has been analysed, regarding detailed process flow and time dedicated for its performance. In accordance to its status, it has possibility to be reduced by different strategies. Companies willing to optimize their processes tend to measure them but also tend to have objective view on the core process structure. To be open to change and to be continuous in evaluation is of crucial matter for any process optimization. Picking orders in this case and solution provided in the paper is only one of the many possibilities to approach process evaluation. After a detailed analysis, observed on broad data that include seasonality, KPIs, types of goods, performance and the structure of any kind of warehouse process, it can be well modified.

By optimizing order picking as proposed, it is considered that the processes would run more efficiently. The optimization includes predefining WMS data and reorganization of dedicated storage locations directly influencing the time consuming order picking, which is presented with the proposed changes in the observed company's warehouse layout. The evaluation of effectiveness and effectivity of a certain process, such as order picking, should be constantly supervised in the form of analysis and chronographically measured to be controlled and reduced.

The conducted research and research on the Croatian market provided by the authors before, implicated the lack of process control. Although with a strong position on the market the companies are focused on the financial aspect, while operational approach is often marginalized. The processes structure should be submitted to the analysis and potential change in accordance to any criteria, increase of units stored, customer orders, number of employees, order picking methods, layout change, etc. Case studies should be carried out more commonly where in the form of cooperation between science and market they can develop the basis of solutions for supply chain experts.

JOSIP HABAZIN, mag.ing.traff. ${ }^{1}$

E-mail: josip.habazin@gmail.com

ANTONIA GLASNOVIĆ, mag.ing.traff. ${ }^{1}$

E-mail: aglasnovic11@gmail.com

dr. sc. IVONA BAJOR ${ }^{1}$

E-mail: ibajor@fpz.hr

${ }^{1}$ Sveučilište u Zagrebu, Fakultet prometnih znanosti

Vukelićeva 4, 10000 Zagreb, Hrvatska 


\section{SKLADIŠNI PROCES KOMISIONIRANJA: STUDIJA SLUČAJA U MLJEKARSKOJ INDUSTRIJI U REPUBLICI HRVATSKOJ}

\section{SAŽETAK}

Pravilno funkcioniranje skladišnih procesa važno je za operativno poboljšanje i opći napredak u logističkom opskrbnom lancu. Komisioniranje se smatra jednim od važnijih procesa iz grupe. Tijekom komisioniranja u skladištima ljudski rad je značajan, s glavnim ciljem reduciranja vremena trajanja procesa što je moguće više, odnosno na minimum. Nekoliko je različitih metoda komisioniranja, a danas se najčešće razvijaju i značajno ovise o vrsti robe, skladišnoj opremi, i dr., a metode koje se izdvajaju jesu skeniranje $i$ komisioniranje glasom.

\section{KLUČNE RIJEČI}

skladištenje; komisioniranje; analiza izvedbe; opskrbni lanac; vrsta robe;

\section{REFERENCES}

[1] Bartholdi JJ, Hackman ST. Warehouse and distribution science, the supply chain and logistics institute. Atlanta: School of Industrial and Systems Engineering; 2011.

[2] Richards G. Warehouse management: a complete guide to improving efficiency and minimizing costs in the modern warehouse. London: Kogan Page; 2014.

[3] Croatia. [Basic Structural Business Indicators of Enterprises]. Zagreb: Croatian Bureau of Statistics; 2014. Croatian
[4] Mendes P. Demand driven supply chain: a structured and practical roadmap to increase profitability. Berlin: Springer Berlin Heidelberg; 2011.

[5] Lee JA, Chang YS, Shim H, Cho S. A study on the picking process time. Procedia Manufacturing. 2015:3:731738.

[6] Saif A, Elhedhli S. Cold supply chain design with environmental considerations: a simulation-optimization approach. European Journal of Operational Research. 2015;251(1):274-287. doi: http://dx.doi. org/10.1016/j.ejor.2015.10.056

[7] Lu W, McFarlane D, Giannikas V, Zhang Q. An algorithm for dynamic order-picking in warehouse operations. European Journal of Operational Research. 2016;248(1):107-122. doi: http://dx.doi. org/10.1016/j.ejor.2015.06.074

[8] Thomas LM, Meller RD. Developing design guidelines for a case-picking warehouse. International Journal of Production Economics. 2015;170(Part C):741-762. doi: http://dx.doi.org/10.1016/j.ijpe.2015.02.011

[9] Pazour JA, Carlo HJ. Warehouse reshuffling: insights and optimization. Transportation Research Part E: Logistics and Transportation Review. 2015;73:207-226. doi: http://dx.doi.org/10.1016/j.tre.2014.11.002

[10] Rakesh V, Adil GK. Layout optimization of a three dimensional order picking warehouse. IFAC-PapersOnLine. 2015;48(3):1155-1160. doi: 10.1016/j.ifacol.2015.06.240

[11] Kang JH, Kim YD. Inventory control in a two-level supply chain with risk pooling effect. International Journal of Production Economics. 2012;135(1):116-124. doi: http://dx.doi.org/10.1016/j.ijpe.2010.11.014

[12] Zhang Y. Correlated storage assignment strategy to reduce travel distance in order picking. IFAC-PapersOnLine. 2016;49(2)30-35. doi:10.1016/j.ifacol.2016.03.006 